\title{
Surgical Strategy for Rectovaginal Fistula After Colorectal Anastomosis at a High-volume Cancer Center According to Image Type and Colonoscopy Findings
}

\author{
KOJI KOMORI, TAKASHI KINOSHITA, TAIHEI OSHIRO, AKIRA OUCHI, SEIJI ITO, TETSUYA ABE, \\ YOSHIKI SENDA, KAZUNARI MISAWA, YUICHI ITO, SEIJI NATSUME, EIJI HIGAKI, MASATAKA OKUNO, \\ TAKAHIRO HOSOI, TAKUYA NAGAO, AINA KUNITOMO, SATOSHI OKI, JIN TAKANO, \\ YASUHITO SUENAGA, SHINGO MAEDA, HIDEYUKI DEI, YOSHIHISA NUMATA and YASUHIRO SHIMIZU
}

Department of Gastroenterological Surgery, Aichi Cancer Center Hospital, Nagoya, Japan

\begin{abstract}
Background/Aim: The reported incidence of rectovaginal fistula is very low. Although some case reports have described surgical procedures, no systematic approach to the treatment of rectovaginal fistula according to diagnostic image and colonoscopy findings has been proposed. We present a comprehensive surgical strategy for rectovaginal fistula after colorectal anastomosis according to diagnostic image and colonoscopy findings. Patients and Methods: This retrospective study included 11 patients who developed rectovaginal fistula after colorectal anastomosis. Rectovaginal fistula was classified into 4 types according to contrast enema images and colonoscopy findings, i.e., "Alone type", "Dead space type", "Anastomotic stricture type”, and "Dead space and Anastomotic stricture type". The surgical strategies were "Diversion (Stoma)", "Percutaneous drainage", "Anastomotic stricture type", "Endoscopic balloon dilation", "Curettage of foreign bodies", "Simple full-thickness closure", "Split-thickness closure”, "Pedicled flaps packing", and "Reanastomosis". The surgical strategy appropriate for each rectovaginal fistula type was investigated. Results: Among "Alone type" cases, 5 (71.4\%) healed with "only Diversion (Stoma)". "Alone type" cases $(n=11)$ and all other cases $(n=4)$ healed with "only Diversion (Stoma)" ( $n=5)$ or any other method ( $n=6) \quad(p=0.022)$. Conclusion: For treatment of rectovaginal fistula after colorectal anastomosis, less invasive treatment approaches should be attempted first.
\end{abstract}

Correspondence to: Koji Komori, MD, Department of Gastroenterological Surgery, Aichi Cancer Center Hospital, 1-1, Kanokoden, Chikusa, Nagoya, Aichi 464-8681, Japan. Tel: +81 527626111, Fax: +81 527635233, e-mail: kkomori@aichi-cc.jp

Key Words: Rectovaginal fistula, colorectal anastomosis, highvolume cancer center.
The reported incidence of rectovaginal fistula is very low (13 ). However, it is very difficult to achieve complete healing in an established fistula (4). Previously published case reports have described some surgical procedures, with emphasis on reconstructive surgery, such as use of a gracilis muscle flap (5). Although a few reviews on the treatment of rectovaginal fistula have been published (4), no systematic approach to treatment according to diagnostic image and colonoscopy findings has been proposed.

We have developed a comprehensive surgical strategy for rectovaginal fistula after colorectal anastomosis according to diagnostic image and colonoscopy findings at a high-volume cancer center.

\section{Patients and Methods}

This retrospective study included 11 patients who developed rectovaginal fistula after colorectal anastomosis. Out of 1,455 surgical cases, $9(0.62 \%)$ underwent resection for a primary rectal lesion at the Department of Gastroenterological Surgery, Aichi Cancer Center Hospital between July 2004 and June 2018 (14 years). Two cases underwent resection for a primary rectal lesion at other hospitals in the same period. This research project was approved by the Ethics Committee of our institution (2019-1-034) and conformed to the provisions of the Declaration of Helsinki.

Rectovaginal fistula was classified into four types according to diagnostic contrast enema images and colonoscopy findings, i.e., "Alone type" $(n=7,63.6 \%)$, "Dead space type" $(n=1,9.1 \%)$, "Anastomotic stricture type" $(\mathrm{n}=1,9.1 \%)$, and "Dead space and Anastomotic stricture type" $(\mathrm{n}=2,18.2 \%)$.

"Alone type" was defined as the presence of a rectovaginal fistula without dead space or an anastomotic stricture (Figure 1). "Dead space type" was defined as the presence of a rectovaginal fistula with dead space (Figure 2). "Anastomotic stricture type" was defined as the presence of a rectovaginal fistula with an anastomotic stricture (Figure 3). "Dead space and Anastomotic stricture type" was defined as the presence of a rectovaginal fistula with an anastomotic stricture and dead space (Figure 4). All cases showed eventually complete healing. 
Table I. The choice of surgical strategy according to each rectovaginal fistula type.

\begin{tabular}{lcccc}
\hline & $\begin{array}{c}\text { Only Diversion } \\
\text { (Stoma) }(\mathrm{n}=5)\end{array}$ & Not Diversion (Stoma) only (n=6) \\
\cline { 3 - 5 } & & $\begin{array}{c}\text { Curettage of } \\
\text { foreign bodies with } \\
\text { Diversion }(\mathrm{n}=1)\end{array}$ & $\begin{array}{c}\text { Pedicled flaps } \\
\text { packing with } \\
\text { Diversion (n=2) }\end{array}$ & $\begin{array}{c}\text { Re-anastomosis } \\
\text { with } \\
\text { Diversion (n=3) }\end{array}$ \\
\hline $\begin{array}{l}\text { Alone type }(\mathrm{n}=7) \\
\text { Not Alone type }(\mathrm{n}=4)\end{array}$ & $5(71.4 \%)$ & $1(14.3 \%)$ & $1(14.3 \%)$ & 0 \\
$\quad \begin{array}{l}\text { Dead space type }(\mathrm{n}=1) \\
\text { Anastomotic stricture type }(\mathrm{n}=1)\end{array}$ & 0 & 0 & $1(100.0 \%)$ & $1(100.0 \%)$ \\
Dead space and Anastomotic stricture type $(\mathrm{n}=2)$ & 0 & 0 & 0 & $2(100.0 \%)$ \\
\hline
\end{tabular}

Figure 5 shows the surgical strategy for rectovaginal fistula in our hospital. In all 4 types, "Diversion (Stoma)" was initially selected, with the expectation of complete healing. In the absence of complete healing in a "Dead space type" case, "Percutaneous drainage" was then selected. In "Anastomotic stricture type" cases, "Endoscopic balloon dilation" was initially selected. In "Dead space and Anastomotic stricture type" cases, "Percutaneous drainage" and "Endoscopic balloon dilation" were initially selected, with subsequent conversion to "Alone type" and the expectation of complete healing. In further absence of complete healing, "Curettage of foreign bodies", "Simple full-thickness closure", "Split-thickness closure" and "Pedicled flaps packing" were selected. "Curettage of foreign bodies" was used to treat infected granulation tissue or staple pins (Figure 6). "Simple full-thickness closure" was used to treat rectovaginal fistula involving the posterior vaginal wall and anterior rectal wall as a unit. "Splitthickness closure" was used to treat rectovaginal fistula with involvement of the anterior rectal wall in a horizontal direction. The vaginal wall was then closed vertically at right angles to the rectal wall or closed vertically in parallel with the rectal wall (Figure 7).

In further absence of complete healing without evidence of local relapse, "Reanastomosis" was selected. "Diversion (Stoma)" was ultimately required for closure.

The surgical strategy appropriate for each rectovaginal fistula type was investigated. Rectovaginal fistulas were grouped into two categories, i.e., "Alone type" and all other types: "Dead space type", "Anastomotic stricture type" and "Dead space and Anastomotic stricture type". Similarly, the surgical strategies were grouped into two categories, i.e., "only Diversion (Stoma)" and all other strategies: "Curettage of foreign bodies (infected granulation tissue, staple pins, etc.)", "Simple full-thickness closure", "Split-thickness closure (vaginal wall at right angles with the rectal wall and vaginal wall in parallel with the rectal wall)", "Pedicled flaps packing," and "Reanastomosis".

Analyses were performed using the Chi-square test. Statistical significance was set at $p<0.05$.

\section{Results}

Table I shows the choice of surgical strategy according to each rectovaginal fistula type. Among "Alone type" cases, 3 (71.4\%) healed using “only Diversion (Stoma)", 1 (14.3\%) using "Curettage of foreign bodies with Diversion", and 1 (14.3\%) using "Pedicled flaps packing with Diversion". The single "Dead space type" case healed using "Reanastomosis with Diversion". The single "Anastomotic stricture type" case healed using "Pedicled flaps packing with Diversion". Both "Dead space and Anastomotic stricture type" cases $(100.0 \%)$ healed using "Reanastomosis with Diversion". There were no "Simple full-thickness closure" or "Splitthickness closure" cases in this study. Based on these categories, healing in "Alone type $(n=11)$ " and all other cases $(n=4)$ using "only Diversion (Stoma) $(n=5)$ " or all other methods $(\mathrm{n}=6)$ showed statistically significant differences $(p=0.022)$.

\section{Discussion}

Previous case reports on treatment of rectovaginal fistula after colorectal anastomosis did not propose comprehensive approaches. The reported incidence of rectovaginal fistula after low anterior resection is only $0.3-5.1 \%$ (1-3). However, some investigators have reported risk factors for rectovaginal fistula in original research rather than simply as case reports. Watanabe et al. have reported that risk factors for rectovaginal fistula after colorectal anastomosis included prognostic nutritional index, preoperative chemotherapy, tumor size, intraoperative bleeding, and lateral lymph node dissection (2). Matthiessen et al. have reported that risk factors included low anastomosis, preoperative radiotherapy, and stage IV cancers (3).

Das et al. have reviewed previous reports on rectovaginal fistula diagnosis and surgical intervention and noted that sphincteroplasty and gracilis muscle flaps were generally recommended (4).

However, there have been no reports on a systematic approach to conservative treatment for rectovaginal fistula after colorectal anastomosis. Our study is the first to describe systematic management. In particular, the classification of rectovaginal fistula based on diagnostic images and colonoscopy findings has not been reported previously. Nevertheless, our surgical techniques were not novel and had 


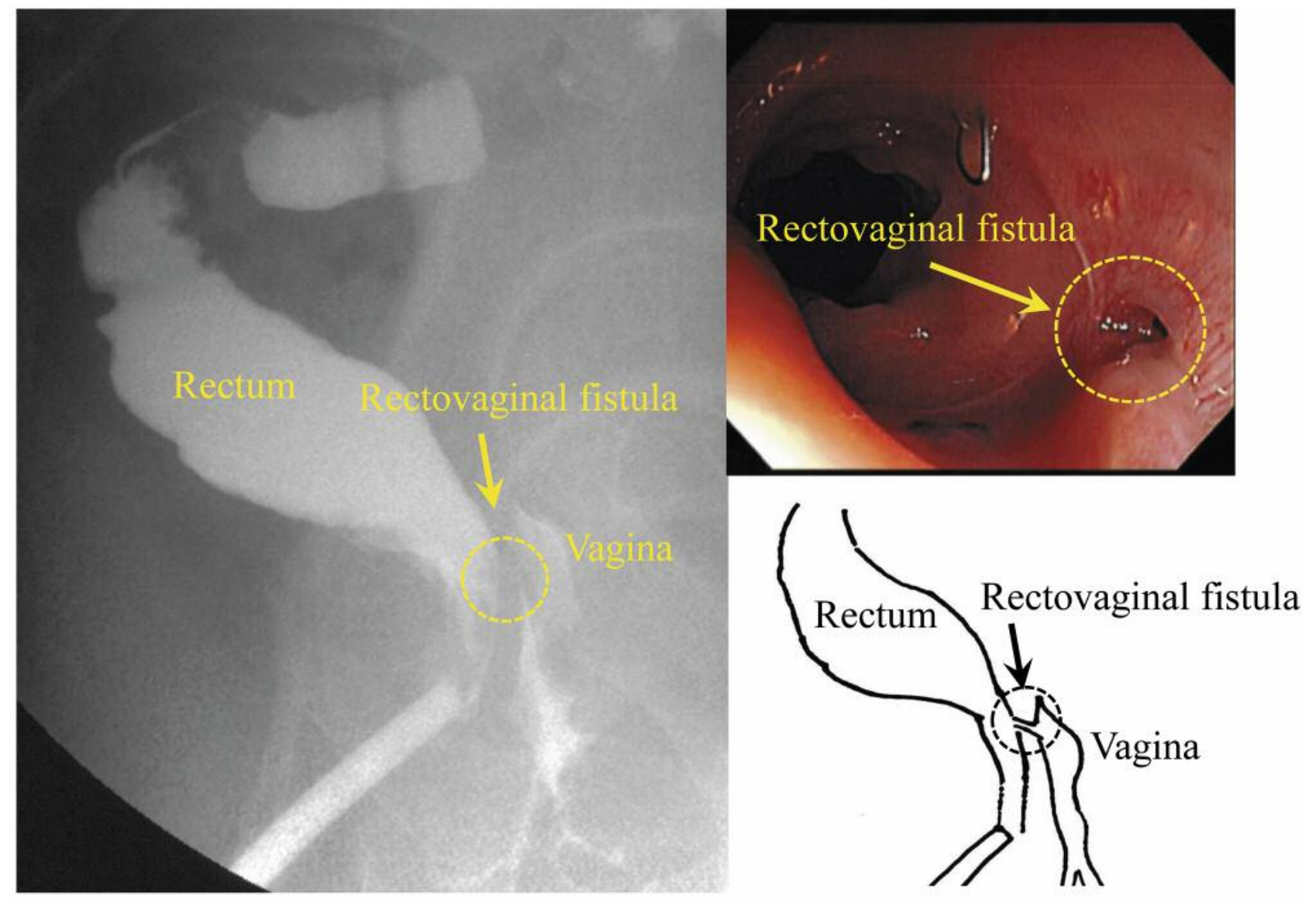

Figure 1. Contrast enema is shown on the left and endoscopy findings on the upper right. A schematic of the "Alone type" (yellow and black arrows and circled dots) is shown on the lower right.
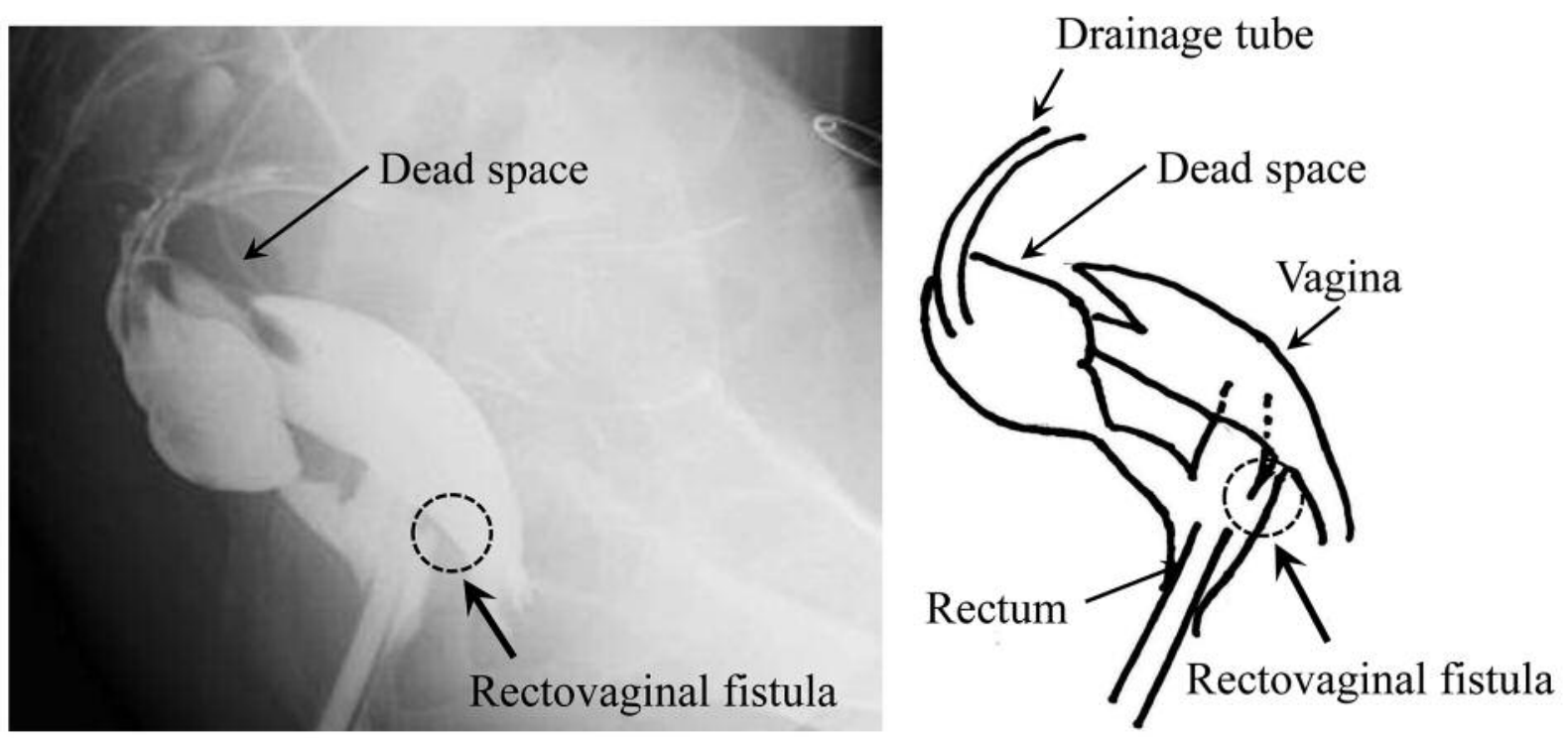

Figure 2. Contrast enema on the left shows the "Dead space type" (black arrow and circled black dots), with a corresponding schematic on the right. 


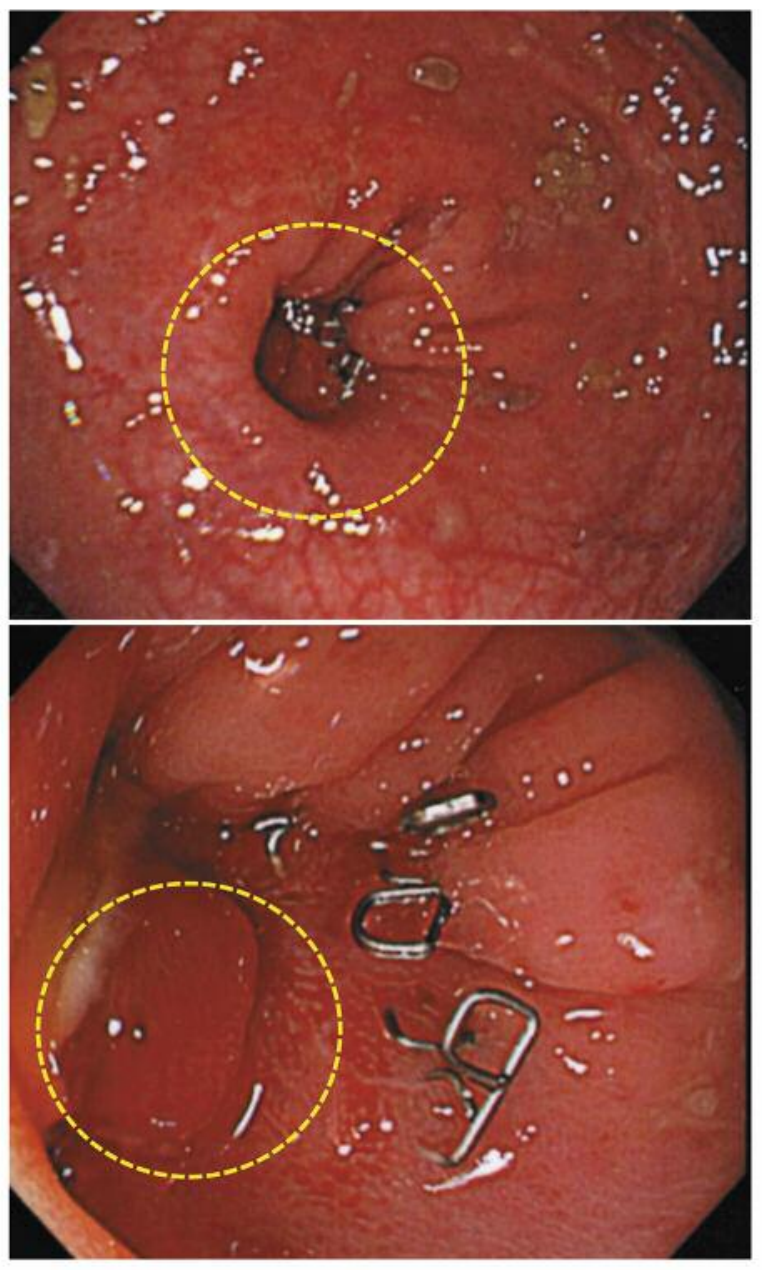

\section{Anastomotic stricture}

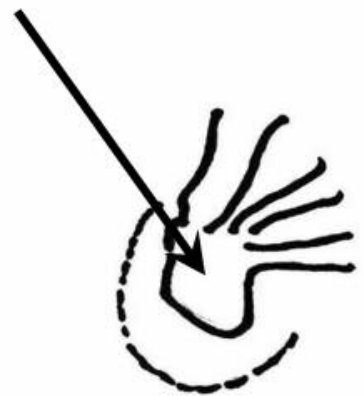

Rectovaginal fistula

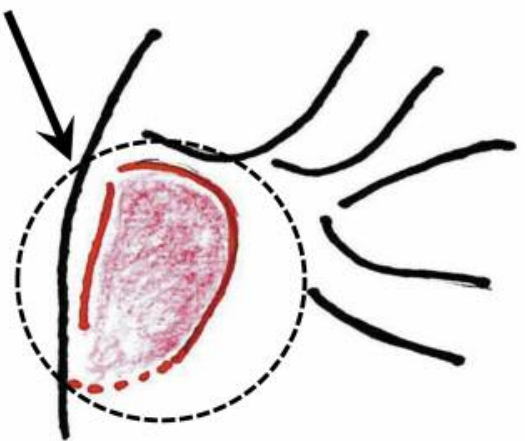

Figure 3. Endoscopy findings on the upper left show an anastomotic stricture (circled yellow dots), with a corresponding schematic on the upper right. Endoscopy findings on the lower left show the "Anastomotic stricture type" (circled yellow dots). The intravaginal space is shown behind the anastomotic stricture as a schematic on the lower right.

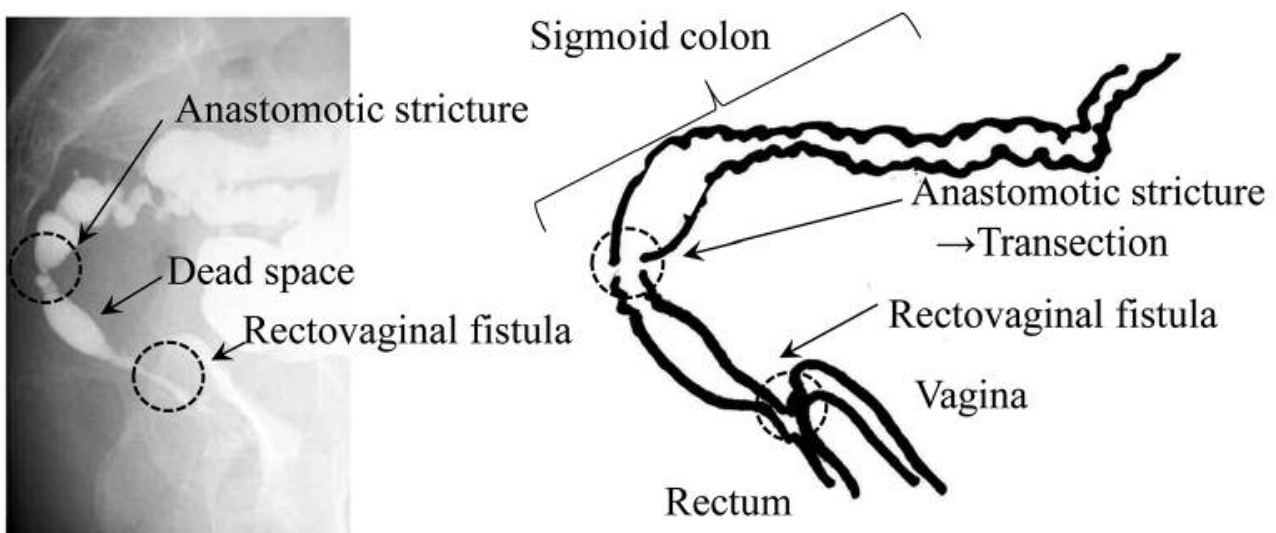

Figure 4. Contrast enema on the left shows the "Dead space and Anastomotic stricture type" (black arrow and circled black dots), with a schematic on the right. The anastomotic stricture is opposite to the rectovaginal fistula, and the specific transection is shown. 


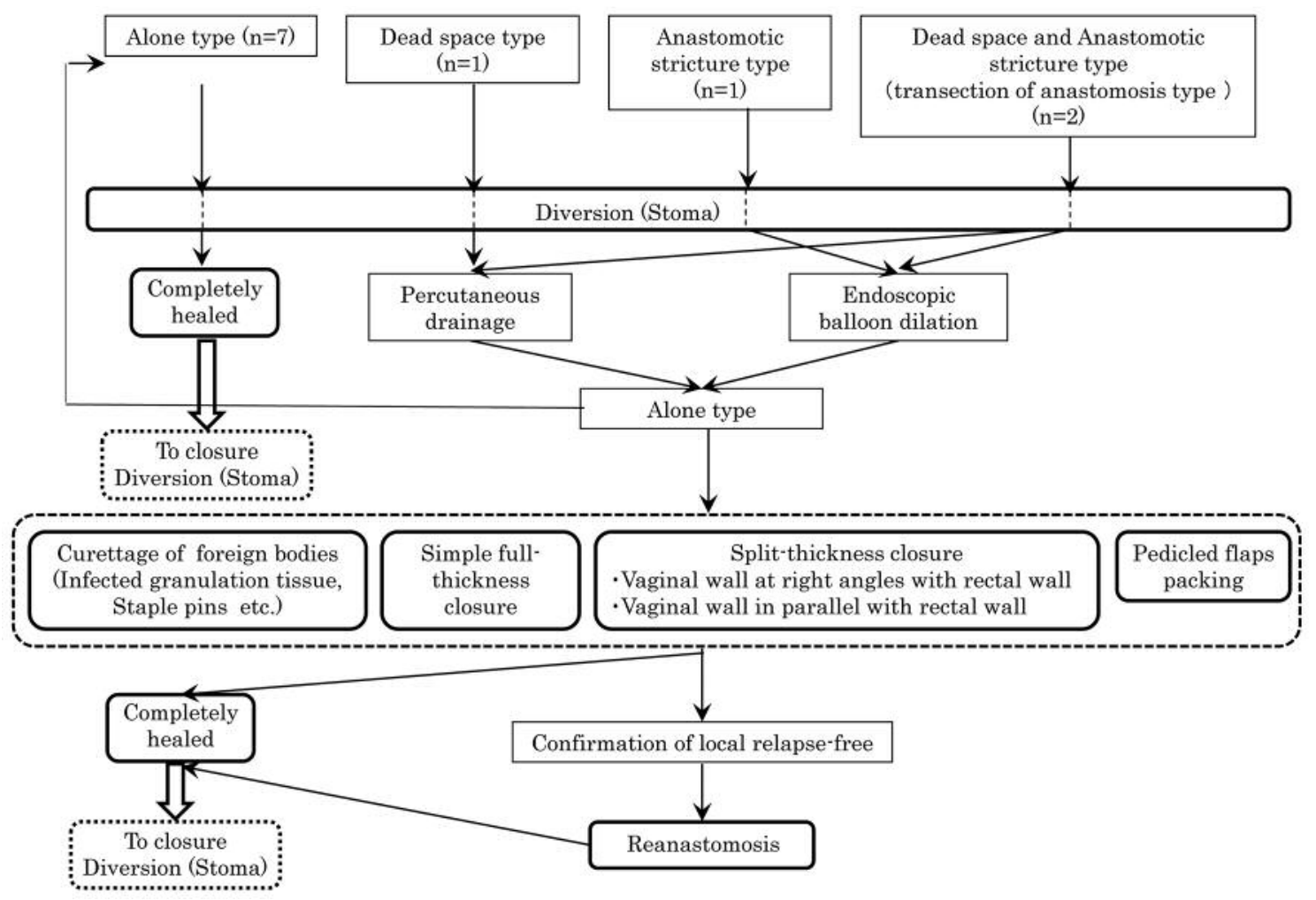

Figure 5. Schematic of surgical approach for rectovaginal fistula.

been reported previously. With regard to "Curettage of foreign bodies", Onishi et al. have reported that staple pin removal and simple, full-thickness rectal wall closure with diverting loop colostomy led to healing (6). With regard to "Simple full-thickness closure", Maeda et al. have reported that transvaginal anterior levatorplasty is effective for the treatment of mid or low rectovaginal fistula using puborectalis and pubococcygeal muscles (7). With regard to "Pedicled flaps packing", Rottoli et al. have reported that gracilis muscle transposition was associated with a high success rate for rectovaginal fistula (5). However, Park et al. have reported surgical failure when a gracilis muscle flap was used for rectovaginal fistula repair in cases with a history of more than two courses of radiotherapy (8).

Our data suggested that healing occurred in most, but not all cases of "Alone type" rectovaginal fistula using "only Diversion (Stoma)" and that more aggressive treatments were unnecessary. In the management of rectovaginal fistula after colorectal anastomosis, less invasive treatment approaches should be attempted first. Emoto et al. have reported that conservative treatment using a double-stapling technique without surgical intervention may be effective for rectovaginal fistula after colorectal anastomosis when there is no evidence of defecation through the vagina (9). Such a case may be uncommon, but their study supports our conclusions. Our surgical strategy for rectovaginal fistula after colorectal anastomosis, as shown in Figure 5, is appropriate and logical, and we anticipate wide acceptance.

\section{Conclusion}

The accurate diagnosis of rectovaginal fistula is likely to prevent unnecessarily aggressive treatment. In the case of rectovaginal fistula after colorectal anastomosis, less invasive treatment approaches should be attempted first.

\section{Conflicts of Interest}

The Authors have no conflicts of interest to declare in relation to this study.

\section{Authors' Contributions}

K. K., T. K., T. O., and A. O. conceived and designed the study; K. K., T. K., T. O., and A. O. performed the study; K. K., T. K., T. O., and A. O. recruited patients, collected and processed samples; and K.K. contributed reagents/materials/analysis tools; and K.K. wrote the article. All Authors declare they significantly participated in creation of the study. All Authors read and approved the final article. 

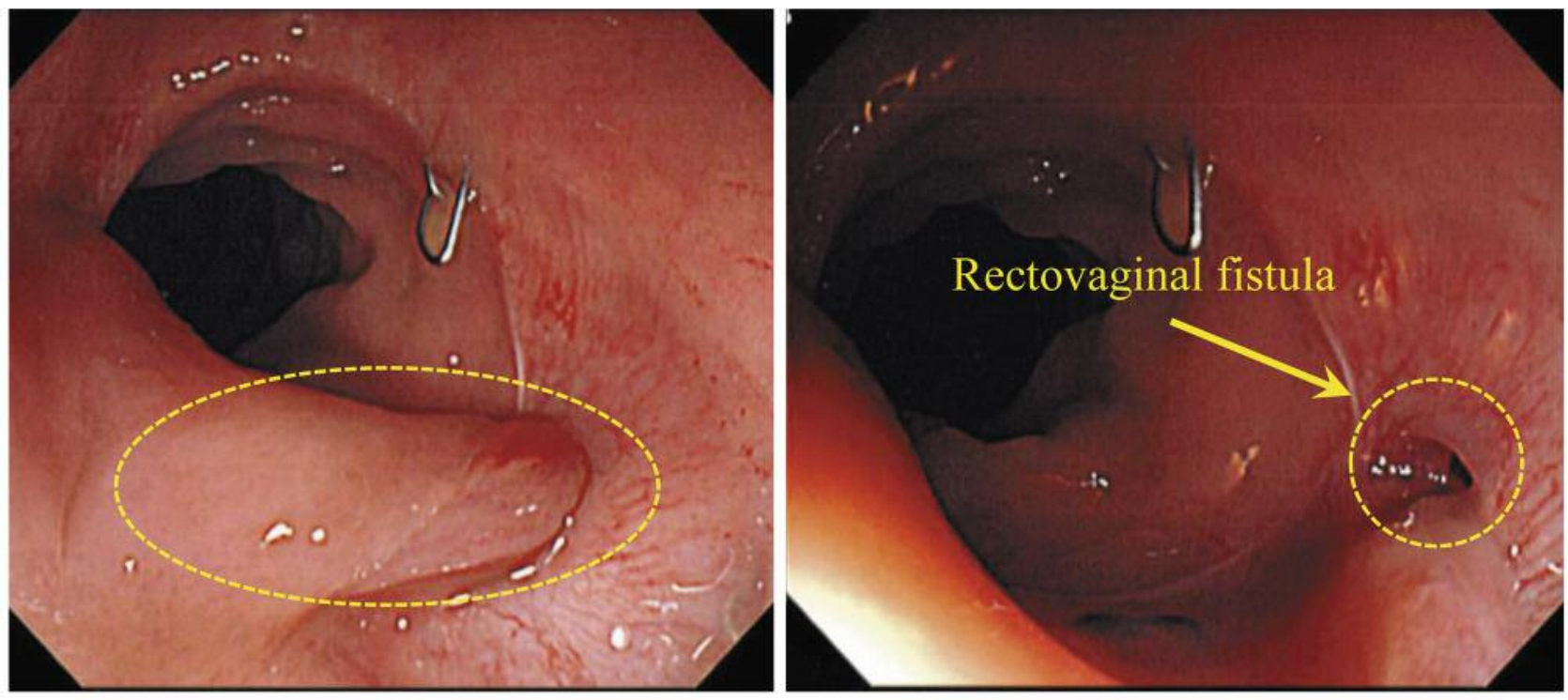

Figure 6. Endoscopy findings on the left show infected granulation tissue covering a rectovaginal fistula (circled yellow dots). Endoscopy findings on the right show the rectovaginal fistula after curettage of infected granulation tissue (yellow arrow and circled yellow dots).

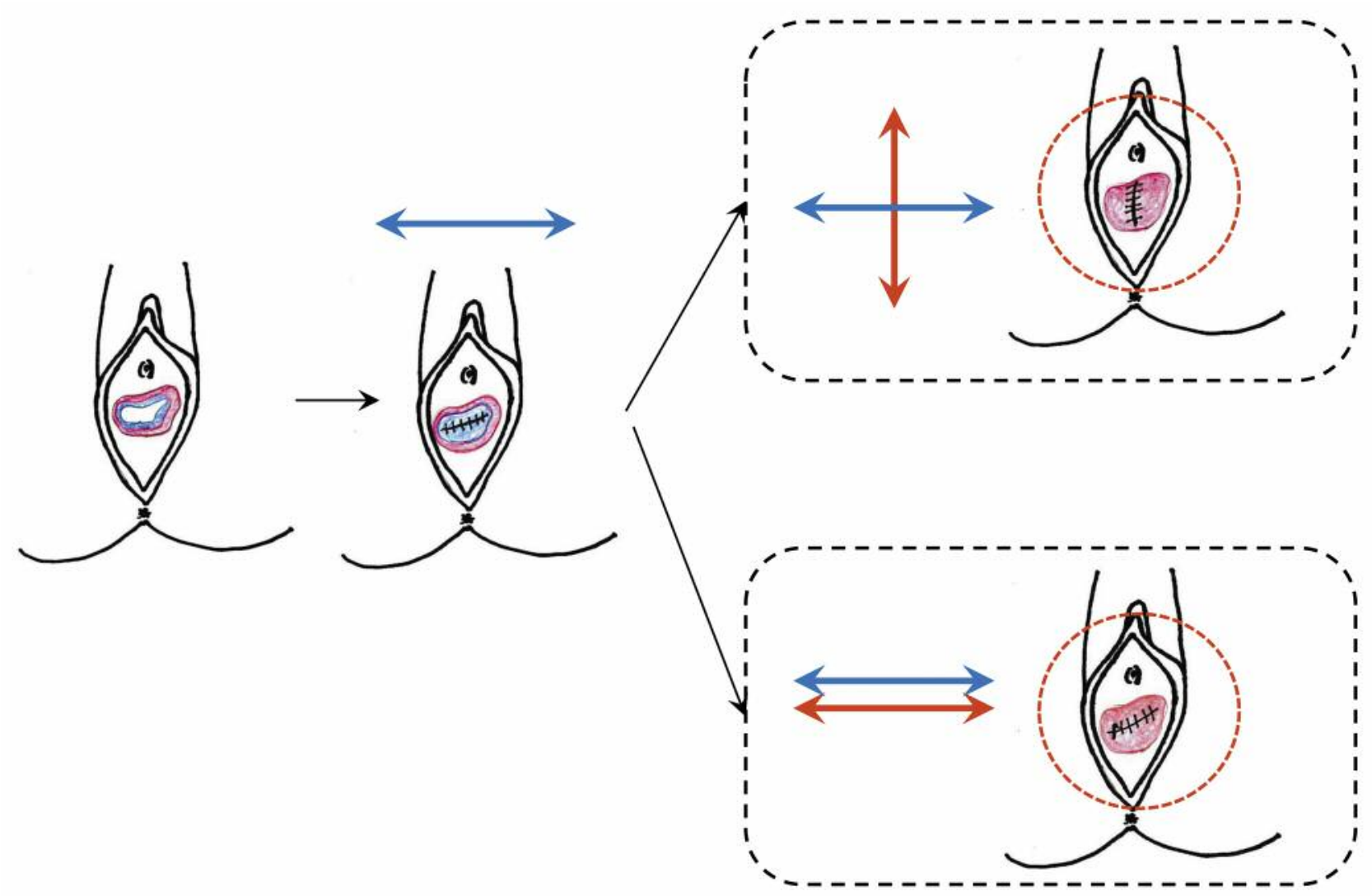

Figure 7. Schematic of split-thickness closure. First, the anterior rectal wall is closed (blue double arrow on the left). Second, the vaginal wall is closed at right angles to the rectal wall (red double arrow on the upper right, circled red dots), or in parallel with the rectal wall (red double arrow on the lower right, circled red dots). 


\section{References}

1 Akiyoshi T, Ueno M, Fukunaga Y, Fukunaga Y, Nagayama S, Fujimoto $\mathrm{Y}$, Konishi T, Kuroyanagi $\mathrm{H}$ and Yamaguchi T: Incidence of and risk factors for anastomotic leakage after laparoscopic anterior resection with intracorporeal rectal transection and double-stapling technique anastomosis for rectal cancer. Am J Surg 202(3): 259-264, 2011. PMID: 21871980. DOI: $10.1016 /$ j.amjsurg.2010.11.014

2 Watanabe J, Ota M, Kawaguchi D, Shima H, Kaida S, Osada S, Kamimukai N, Kamiya N, Ishibe A, Watanabe K, Matsuyama R, Akiyama H, Ichikawa Y, Oba M and Endo I: Incidence and risk factors for rectovaginal fistula after low anterior resection for rectal cancer. Int J Colorectal Dis 30(12): 1659-1666, 2015. PMID: 26248793. DOI: 10.1007/s00384-015-2340-5

3 Matthiessen P, Hansson L, Sjodahl R and Rutegard J: Anastomotic-vaginal fistula (AVF) after anterior resection of the rectum for cancer--occurrence and risk factors. Colorectal Dis 12(4): 351-357, 2010. PMID: 19220383. DOI: 10.1111/j.14631318.2009.01798.x

4 Das B and Snyder M: Rectovaginal Fistulae. Clin Colon Rectal Surg 9(1): 50-56, 2016. PMID: 26929752. DOI: 10.1055/s-00351570393

5 Rottoli M, Vallicelli C, Boschi L, Cipriani R and Poggioli G: Gracilis muscle transposition for the treatment of recurrent rectovaginal and pouch-vaginal fistula: is Crohn's disease a risk factor for failure? A prospective cohort study. Updates Surg 70(4): 485-490, 2018. PMID: 29982963. DOI: 10.1007/s13304018-0558-9

6 Onishi K, Ogino A, Saida Y and Maruyama Y: Repair of a recurrent rectovaginal fistula using gluteal-fold flap: report of a case. Surg Today 39(7): 615-618, 2009. PMID: 19562452. DOI: $10.1007 / \mathrm{s} 00595-008-3883-7$
7 Maeda K, Koide Y, Hanai T, Sato H, Masumori K, Matsuoka H and Katsuno $\mathrm{H}$ : The long-term outcome of transvaginal anterior levatorplasty for intractable rectovaginal fistula. Colorectal Dis 17(11): 1002-1006, 2015. PMID: 25891199. DOI: 10.1111/ codi.12977

8 Park SO, Hong KY, Park KJ, Chang H, Shin JY and Jeong SY: Treatment of rectovaginal fistula with gracilis muscle flap transposition: long-term follow-up. Int J Colorectal Dis 32(7): 1029-1032, 2017. PMID: 28210852. DOI: 10.1007/s00384-0172784-x

9 Emoto S, Nozawa H, Yoneyama S, Murono K, Kaneko M, Sasaki K, Otani K, Nishikawa T, Tanaka T, Hata K, Kiyomatsu T, Kawai K, Omata K, Noguchi T, Masuda K, Sakata H, Tajima Y, Hidemura A, Suzuki H, Ishimaru $M$ and Watanabe T: Rectovaginal fistula after low anterior resection for rectal cancer healed by nonoperative treatment. Int Int J Surg Case Rep 41: 121-123, 2017. PMID: 29073547. DOI: 10.1016/j.ijscr.2017. 10.019
Received July 6, 2019

Revised July 11, 2019

Accepted July 12, 2019 